\title{
RAZVOJNE KARATERISTIKE DEVOJČICA PREDŠKOLSKOG UZRASTA RAZLIČITIH URBANIH SREDINA
}

\author{
Darko Stojanović ${ }^{1}$, Nikola Stojanović ${ }^{1}$ i Ratomir Đurašković ${ }^{1}$ \\ ${ }^{1}$ Fakultet sporta i fizičkog vaspitanja, Univerzitet u Nišu, Srbija
}

Kratki naučni članak

\section{SAŽETAK}

Rast $i$ razvoj čoveka je pod uticajem unutrašnjih genetskih $i$ spoljašnjih faktora. Longitudinalne i transverzalne dimenzije skeleta su u velikom procentu genetski uslovljene, za razliku od cirkularnih dimenzija, mase tela i potkožnog masnog tkiva. Cilj istraživanja je bio utvrđivanje razlika u razvojnim karakteristikama devojčica obdaništa Vranja $i$ Užica. Istraživanje je obavljeno u vrtićima Vranja $i$ Užica. Ukupan uzorak je obuhvatio 136 devojčica, od kojih 72 ispitanice prosečne starosti 5 godina i 8 meseci iz Užica i 64 ispitanice starosti 5 godina $i 7$ meseci iz Vranja. Merenje antropometrijskih karakteristika je vršeno standardnim instrumentima po metodologiji koju preporučuje Internacionalni biološki program (Weiner $i$ Lourie, 1981). Prosečna visina devojčica vrtića iz Vranja iznosi

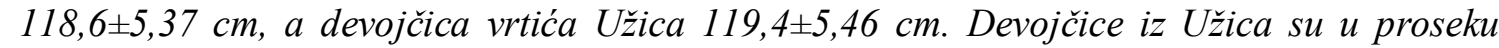
numerički veće visine tela $u$ odnosu na devojčice Vranja, ali ne $i$ statistički značajno. Rezultati ukazuju da postoji statistički značajna razlika u dužini nogu. Prosečna dužina nogu

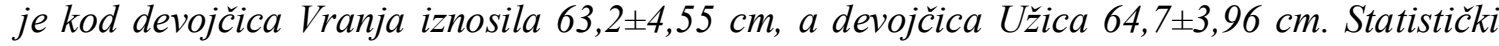
značajno veću širinu karlice imaju devojčice Vranja u odnosu na devojčice Užica. U ostalim merenim antropometrijskim varijablama nije utvrđena statistički značajna razlika.

Ključne reči: razvojne karateristike, devojčice, predškolski uzrast, urbana sredina

\section{UVOD}

Osnovni zadatak predškolskih ustanova je da daju optimalni doprinos telesnom rastu i razvoju dece, razvoju njihovih motoričkih i funkcionalnih sposobnosti, kao i osposobljavanju za življenje i stvaralački rad u zajednici (Bala, Popović i Madić, 2005).

Ispitivanjem morfoloških karateristika dobijamo primarnu informaciju o somatskom statusu čoveka, koji je određen antropometrijskim dimenzijama. Pitanje je pod kojim su uticajem te dimenzije dodatno razvijene (npr. fizičkih aktivnosti ili drugih ekosocijalnih činioca). Antropometrijske karakteristike se razlikuju u odnosu na pol, uzrast i genetičko-ekosocijalne uslove (Gajev, 2009).

Rast i razvoj dece je pod velikim uticajem genetskih i faktora sredine u kojoj se razvijaju i rastu. Spoljašni faktori su značajni, kako bi se postigao genetski maksimum poligenske šeme rasta. Uticaj spoljašnjih faktora (sredine) je u predškolskom uzrastu veći u odnosu na naredne periode rasta i razvoja. Od spoljašnjih faktora socijalni status roditelja je od velikog uticaja za optimalan rast i razvoj deteta. Spontani i organizavani oblici fizičkih aktivnosti u predškolskom uzrastu su značajni, kako sa motoričkog, tako i sa umnog i funkcionalnog aspekta razvoja. U ovoj fazi je neophodno da fizičke aktivnosti budu odgovarajućeg intenziteta, prilagođene uzrastu i fizičkim sposobnostima, kako kalendarskoj, tako i biološkoj starosti dece (Đurašković, 2009).

U ovom uzrastu godišnji priraštaj visine i ostalih antropometrijskih pokazatelja dece nije tako izražen, te se može reći da je dete u relativno stabilnoj fazi rasta i razvoja (Đorđić, Bala, 
Popović i Sabo, 2006). Fizički rast i razvoj u određenom procentu može zavisiti i od sredine u kojoj se odvija. Pod ovim se podrazumeva ruralna i urbana sredina, veće i niže nadmorske visine (Nikolić i Paranosić 1980). Navike zdravog života formiraju se u predškolskom i mlađem školskom uzrastu, a rast i razvoj se odvija u relativno pravilnim etapama, za razliku od pubertetske faze.U cilju objektivnog ocenjivanja rasta i razvoja koriste se metodom standarda kojom se upoređuju izmereni antropometrijski parametri sa istim pokazateljima ispitanika iste starosti i pola (Mišigoj-Duraković, 2008). Neophodno je voditi računa o činjenici da dete nije "umanjeni čovek", te iz tih razloga ono ima sopstveni put razvoja morfoloških i funkcionalno-fizioloških karakteristika. Informacije o rastu dece u visinu i njihovoj masi tela često se koriste u proceni zdravstvenog statusa i njihove normalne uhranjenosti i procene njihovog tempa rasta i razvoja (Božić-Krstić, Rakić i Pavlica, 2003).

Ovo istraživanje ima za cilj utvrđivanje postojanja razlika antropometrijskih karakteristika devojčica predškolskog uzrasta urbanih sredina Vranja i Užica.

\section{METODE}

Ukupan uzorak je obuhvatio 136 devojčica, od kojih 72 ispitanice prosečne starosti 5 godina i 8 meseci iz Užica i 64 ispitanice starosti 5 godina i 7 meseci iz Vranja. Sve ispitanice su pohađale obdanište i bile su zdrave kada su vršena merenja njihovih antropometrijskih karakteristika. Procena antropometrijskih karakteristika je obuhvatila mere longitudinalne, transverzalne i cirkularne dimenzionalnosti skeleta, kao i potkožnog masnog tkiva. Izmerene su sledeće mere:

I - Za procenu longitudinalne dimenzionalnosti skeleta :

1. telesna visina (VIST),

2. prognozirana konačna telesna visina (PKOVIS),

3. dužina noge (DUNO),

4. dužina ruke (DURU),

II - Za procenu transverzalne dimenzionalnosti skeleta:

5. širina ramena (ŠIRA),

6. širina karlice (ŠIKA),

7. širina kukova (ŠIKU),

III - Za procenu cirkularne dimenzionalnosti skeleta:

8. telesna masa (MAST),

9. indeks telesne mase (BMI),

10. obim grudnog koša (OGK),

11. obim nadlaktice (ONADL),

12. obim nadkolenice (ONADK),

IV - Za procenu potkožnog masnog tkiva:

13. kožni nabor nadlakta (KNNL),

14. kožni nabor leđa (KNLE) i

15. kožni nabor trbuha (KNTRB).

Merenje svih morfoloških mera je provedeno prema uputstvima Internacionalnog biološkog programa (Weiner \& Lourie, 1981).

\section{REZULTATI}

U tabelama 1. i 2. su prikazani deskriptivni statistički parametri devojčica predškolskog uzrasta iz obdaništa u Užicu i Vranju. Inspekcijom istih, na osnovu vrednosti aritmetičkih sredina i minimalnih i maksimalnih rezultata, može se konstatovati da su rezultati svih morfoloških mera normalno distribuirani, osim kod kožnih nabora leđa i trbuha i kod jednih i kod drugih devojčica. 
Tabela 1. Osnovni statistički parametri antropometrijskih karakteristika devojčica obdaništa iz Užica

\begin{tabular}{|c|c|c|c|c|c|}
\hline Varijable & $\mathbf{N}$ & $\mathbf{A S}$ & MIN & MAX & SD \\
\hline GSTAR & 72 & 5.8 & 5.0 & 7.0 & 0.67 \\
\hline VIST & 72 & 119.4 & 107.0 & 132.5 & 5.46 \\
\hline PKOVIS & 72 & 167.2 & 151.0 & 179.0 & 4.57 \\
\hline DUNO & 72 & 64.7 & 56.0 & 73.5 & 3.96 \\
\hline DURU & 72 & 51.3 & 44.8 & 57.7 & 2.99 \\
\hline ŠIRA & 72 & 26.6 & 23.8 & 30.5 & 1.42 \\
\hline ŠIKA & 72 & 19.1 & 16.0 & 23.0 & 1.39 \\
\hline ŠIIKU & 72 & 20.8 & 17.2 & 27.7 & 1.77 \\
\hline MAST & 72 & 22.9 & 16.0 & 35.0 & 4.02 \\
\hline BMI & 72 & 16.02 & 11.70 & 21.63 & 2.02 \\
\hline OGK & 72 & 58.5 & 50.6 & 71.0 & 4.26 \\
\hline ONADL & 72 & 17.8 & 14.4 & 22.6 & 1.78 \\
\hline ONADK & 72 & 36.2 & 26.3 & 54.0 & 4.43 \\
\hline KNNL & 72 & 12.1 & 6.2 & 21.2 & 3.64 \\
\hline KNLE & 72 & 7.5 & 3.6 & 19.0 & 3.60 \\
\hline KNTRB & 72 & 8.0 & 3.0 & 23.4 & 4.70 \\
\hline
\end{tabular}

Legenda: $\mathrm{N}$ - broj ispitanika; AS - aritmetička sredina; MIN - minimalni vrednost; MAX - maksimalna vrednost; SD - standardna devijacija.

Tabela 2. Osnovni statistički parametri antropometrijskih karakteristika devojčica obdaništa iz Vranja

\begin{tabular}{lccccc}
\hline Varijable & N & AS & MIN & MAX & SD \\
\hline GSTAR & 64 & 5.7 & 5.0 & 7.0 & 0.50 \\
\hline VIST & 64 & 118.6 & 109.8 & 131.6 & 5.37 \\
\hline PKOVIS & 64 & 167.1 & 157.0 & 177.7 & 4.89 \\
\hline DUNO & 64 & 63.3 & 52.2 & 73.5 & 4.54 \\
\hline DURU & 64 & 51.5 & 42.5 & 61.8 & 3.10 \\
\hline ŠIRA & 64 & 26.7 & 23.6 & 31.2 & 1.60 \\
\hline ŠIKA & 64 & 19.6 & 16.9 & 22.9 & 1.42 \\
\hline ŠIKU & 64 & 21.1 & 18.9 & 25.5 & 1.45 \\
\hline MAST & 64 & 22.8 & 17.0 & 32.0 & 4.13 \\
\hline BMI & 64 & 16.15 & 12.76 & 22.32 & 2.25 \\
\hline OGK & 64 & 58.8 & 50.2 & 70.5 & 4.70 \\
\hline ONADL & 64 & 17.9 & 15.0 & 23.2 & 1.96 \\
\hline ONADK & 64 & 36.9 & 31.0 & 47.0 & 4.28 \\
\hline KNNL & 64 & 12.8 & 6.0 & 20.6 & 3.92 \\
\hline KNLE & 64 & 8.3 & 3.0 & 19.4 & 3.92 \\
\hline KNTRB & 64 & 9.2 & 3.0 & 24.0 & 4.69 \\
\hline
\end{tabular}

Legenda: $\mathrm{N}$ - broj ispitanika; AS - aritmetička sredina; MIN - minimalni vrednost; MAX - maksimalna vrednost; SD - standardna devijacija.

Analizom razlika (Tabela 3) srednjih vrednosti antropometrijskih karakteristika devojčica obdaništa iz Užica i Vranja, koji pripadaju različitim urbanim sredinama, može se konstatovati da u svim merenim karakteristikama nema statistički značajne razlike, osim u dužini noge, koja je statistički značajno veća kod devojčica iz Užica ( $p=0.049)$, kao i širini karlice, koja je statistički značajno veća kod devojčica iz Vranja $(\mathrm{p}=0.012)$. Posmatrajući numeričke razlike među ispitanicama ove dve urbane sredine, uočava se razlika u konstituciji istih. Devojčice iz Užica su nešto veće visine i dužine nogu, užih kukova i karlice, nešto manjih cirkularnih mera i potkožnog masnog tkiva u odnosu na devojčice iz Vranja. Iz ovih podataka se može konstatovati da su devojčice iz Užica više i gracilne su građe (mezomorfno- 
ektomorfni tip), a devojčice iz Vranja su nešto niže i imaju karakteristike endomorfne građe (prema Šeldonu).

Tabela 3. Razlika aritmetičkih sredina antropmetrijskih karakteristika devojčica obdaništa Užica i Vranja

\begin{tabular}{|c|c|c|c|c|c|c|}
\hline \multirow[t]{2}{*}{ Varijable } & \multicolumn{2}{|c|}{ Obdanište Užice } & \multicolumn{2}{|c|}{ Obdanište Vranje } & \multirow{2}{*}{$\mathbf{t}$} & \multirow{2}{*}{$\mathbf{p}$} \\
\hline & $\mathbf{A S}$ & SD & AS & SD & & \\
\hline GSTAR & 5.8 & 0.67 & 5.7 & 0.56 & 1.634 & 0.104 \\
\hline VIST & 119.4 & 5.46 & 118.6 & 5.37 & 0.874 & 0.383 \\
\hline PKOVIS & 167.2 & 4.57 & 167.1 & 4.89 & 0.102 & 0.918 \\
\hline DUNO & 64.7 & 3.96 & 63.2 & 4.55 & 1.984 & $0.049 *$ \\
\hline DURU & 51.3 & 2.99 & 51.4 & 2.81 & -0.081 & 0.935 \\
\hline ŠIRA & 26.6 & 1.42 & 26.7 & 1.56 & -0.250 & 0.802 \\
\hline ŠIKA & 19.1 & 1.39 & 19.7 & 1.41 & -2.524 & $0.012 *$ \\
\hline ŠIKU & 20.8 & 1.77 & 21.1 & 1.45 & -0.927 & 0.355 \\
\hline MAST & 22.9 & 4.02 & 22.8 & 4.10 & 0.180 & 0.857 \\
\hline BMI & 16.02 & 2.02 & 16.18 & 2.37 & -0.414 & 0.679 \\
\hline OGK & 58.5 & 4.26 & 58.9 & 4.68 & -0.544 & 0.586 \\
\hline ONADL & 17.8 & 1.78 & 17.9 & 1.94 & -0.445 & 0.656 \\
\hline ONADK & 36.2 & 4.43 & 36.7 & 4.21 & -0.713 & 0.476 \\
\hline KNNL & 12.1 & 3.64 & 12.7 & 3.91 & -0.969 & 0.333 \\
\hline KNLE & 7.5 & 3.60 & 8.3 & 4.12 & -1.176 & 0.241 \\
\hline KNTRB & 8.0 & 4.70 & 9.2 & 5.01 & -1.405 & 0.162 \\
\hline
\end{tabular}

\section{DISKUSIJA}

Analizirajući prosečne vrednosti (Tabela 1), dužina ruke $(51.3 \mathrm{~cm})$ devojčica iz obdaništa u Užicu se kreće u granicama normalnih vrednosti za taj uzrast, ali visina tela $(119.4 \mathrm{~cm})$ i dužina noge $(64.7 \mathrm{~cm})$ su nešto veće od normiranih vrednosti (Gerver i DE bruin, 1996) i rezultata istraživanja koja su se bavila razvojnim karakteristikama devojčica ovog uzrasta (Bala, 2009; Mišigoj-Duraković, 2008; Đurašković, 2009). Kada su u pitanju transverzalne mere, takođe se može konstatovati da se i one kreću u granicama normalnih za taj uzrast, obzirom na prijavljene vrednostima u ranijim istraživanjima. Primetna je značajna razlika naših podataka u odnosu na vrednosti širine ramena u karlice do kojih su došli Gerver i DE bruin (1996), gde su vrednosti našeg istraživanja veće, ali se to može tumačiti kao efekat akceleracije u periodu od skoro dvadeset godina. Telesna masa i indeks telesne mase se kreću u granicama normalnih vrednosti za uhranjenost ovog uzrasta devojčica, kao i cirkularne mere (obim grudnog koša, nadlakta i nadkolenice). Vrednosti potkožnog masnog tkiva su nešto veće od onih koje su konstatovane u pomenutim istraživanjima, što navodi na konstataciju da su devojčice uzrasta od 5 do 7 godina iz Užica sa nešto većom telesnom visinom, ali sa manjim procentom mišićne mase u odnosu na masnu komponentu, obzirom da je njihov indeks telesne mase u granicama normalnog, a prema kriterijumima uhranjenosti (Cole, Bellizi, Flegal i Deitz, 2000).

Analizirajući prosečne vrednosti (Tabela 2), visina tela $(119.4 \mathrm{~cm})$, dužina ruke $(51.3$ $\mathrm{cm})$ i dužina noge $(64.7 \mathrm{~cm})$ devojčica iz obdaništa u Vranju se kreću u granicama normalnih vrednosti za taj uzrast (Gerver i DE Bruin, 1996) i rezultata istraživanja koja su se bavila razvojnim karakteristikama devojčica ovog uzrasta (Bala, 2004; Mišigoj-Duraković, 2008; Popović, 2008; Đurašković, 2009). Kada su u pitanju transverzalne mere, takođe se može konstatovati da se i one kreću u granicama normalnih za taj uzrast, obzirom na prijavljene 
vrednostima u ranijim istraživanjima, osim vrednosti širine kukova $(21.1 \mathrm{~cm})$, koja je nešto veća od normalne za taj uzrast. Telesna masa i indeks telesne mase se kreću u granicama normalnih vrednosti za uhranjenost ovog uzrasta devojčica, kao i cirkularne mere (obim grudnog koša, nadlakta i nadkolenice). Vrednosti potkožnog masnog tkiva su nešto veće od onih koje su konstatovane u pomenutim istraživanjima, što navodi na konstataciju da su devojčice uzrasta od 5 do 7 godina iz Vranja sa normalnom telesnom visinom, ali sa manjim procentom mišićne mase u odnosu na masnu komponentu, obzirom da je njihov indeks telesne mase u granicama normalnog, a prema kriterijumima uhranjenosti (Cole, Bellizi, Flegal i Deitz, 2000).

Rast i razvoj čoveka je pod uticajem unutrašnjih i spoljašnjih faktora. Od unutrašnjih najveći uticaj ima genetski faktor. Međutim ovaj uticaj nije identičan na sve latentne dimenzije tela. Longitudinalna dimenzionalnost skeleta je u najvećem procentu pod uticajem nasleđa i ona se kreće od 85 do 98\%, zavisno od autora do autora (Malacko, 1985; Kolarov, 2005; Đurašković, 2009). Prema Nikoliću i Paranosiću (1980) fizički rast i razvoj u određenom procentu može zavisiti i od sredine u kojoj se odvija, a pod tim se podrazumeva ruralna i urbana sredina, veće i niže nadmorske visine, klimatskih uslova i dr.

Istraživanje koje se vršilo na istom uzorku dece predškolskog uzrasta starosti $5+1$ godina, u urbanim sredinama Užica (411 mnv) i Vranja (480mnv), koji se nalaze na približni jednakim nadmorskim visinama, pokazalo je da su visina $i$ analizirane longitudinalne $i$ transverzalne dimenzije tela u granicama normalnog rasta i razvoja za analizirani razvojni period (Gerver i DE bruin, 1996; Mišigoj-Duraković, 2008), sa naznakom da su devojčice iz Užica nešto više i sa dužim nogama u odnosu na devojčice iz Vranja, a da ove druge imaju nešto veće mere kukova i karlice. Ove razlike se verovatno mogu objasniti različitim fizičkim indentitetom stanovništva Zapadne i Istočne Srbije, vodeći se saznanjima da je Zapadna Srbija područje gde preovladava dinarski antropološki tip (po Vladimiru Dvornikoviću, preuzeto od Popović), a u Istočnoj Srbiji slovenski (nordijski) antropološki tip (po Jovanu Cvijiću, preuzeto od Bogdanović). Dinarski antropološki tip ima karakteristike visokih, gracilnih ljudi, sa karakteristično dužim donjim delom tela, dok slovenski (nordijski) karakteriše nešto nižim rastom i dužim gornjim delom tela.

\section{ZAKLJUČAK}

Upoređivanjem antropometrijskih karakteristika devojčica predškolskog uzrasta od pet do sedam godina iz dve urbane sredine koje se nalaze na istoj nadmorskoj visini, ali u različitim delovima Srbije, Užica u zapadnom i Vranja u istočnom delu, može se zaključiti da su devojčice sa zapada Srbije nešto više, sa dužim nogama u odnosu na devojčice sa istoka, koje pak imaju veću širinu karlice i kukova. Devojčice iz Užica spadaju u mezomorfno-ektomorfni tip, a devojčice iz Vranja su nešto niže i imaju karakteristike endomorfne građe.

Ovaj zaključak se može objasniti ranijim saznanjima o različitim fizičkim karakteristikama stanovništva Zapadne i Istočne Srbije, koja potvrđuju da dinarski antropološki tip preovladava u Zapadnoj Srbiji, a slovenski (nordijski) antropološki tip u Istočnoj Srbiji. Uz pretpostavku da je uticaj ostalih unutrašnjih i spoljašnjih faktori na rast i razvoj dece bio jednak za oba uzorka, može se zaključiti da fizički indentitet pojedinih antropoloških tipova ima značajan uticaj na rast i razvoj dece. 


\section{LITERATURA}

Bala, G. (2004). Kvantitativne razlike osnovnih antropometrijskih karakteristika i motoričkih sposobnosti dečaka i devojčica u predškolskom uzrastu. Glasnik Antropološkog društva Jugoslavije, 39, 219-227.

Bala, G., Popović, B. \& Madić, D. (2005). Relationship between motor abilities and school rediness in preschool children. Kinesiologia Slovenica, 11(1), 5-12.

Bogdanović, M. Ljudske rase i njihova razvojna psihologija. Preuzeto 17.12.2014. godine sa: $\mathrm{http}: / /$ enlite.org/dinaric.pdf

Božić-Krstić, V., Rakić, R. \& Pavlica, T. (2003). Telesna visina i masa predškolske i malađe školske dece u Novom Sadu. Glasnik antropološkog društva Jugoslavije, 38, 91-100.

Cole, T.J., Bellizzi, M.C., Flegal, K.M. \& Dietz, W.H. (2000). Establishing a standard definition for child overweight and obesity worldwide: international survey. British Medical journal, 320, 1240-1243.

Đorđić, V., Bala, G., Popović, B. \& Sabo, E. (2006). Fizička aktivnost devojčica i dečaka predškolskog uzrasta. Novi Sad, (RS): Fakultet fizičke kulture.

Đurašković, R. (2009). Sportska medicina. Niš, (RS): M KOPS Centar.

Gajev, A. (2009). Fizička razvijenost i fizičke sposobnosti dece osnovnoškolskog uzrasta. Beograd (RS): Jugoslovenski pregled, Jugoslovneski zavod za sport.

Gerver, M.J.W. \& DE Bruin, R. (1996). Pedijatric Morphometrics. Utreht, (NL): Wetenschappelijke uitgeverij Bunge.

Kolarov, N. (2005). Dete i sport. Sportska medicina, 5(1): 22-26.

Malacko, J. (1985). Uticaj programiranog vežbanja na psihosomatski status dece za sport. Novi Sad, (RS): Fakultet fizičke kulture.

Mišigoj-Duraković, M. (2008). Kinantropologija. Zagreb, (RH): Tiskara Zelinda.

Nikolić, A. \& Paranosić, V. (1980). Selekcija u košarci. Beograd, (RS): „Partizan“.

Popović, B. (2008). Trend razvoja antropometrijskih karakteristika dece uzrasta 4-11 godina. Glasnik Antropološkog društva Srbije, 43, 455-465.

Popović, ¿̌. Fizički indentitet. Preuzeto 17.12.2014. godine sa: http://www.koreni.net/modules.php?name=News\&file=print\&sid=2592

Weiner, J.S. \& Lourie, J.A. (1981). Practical Human Biology. New York, (USA): Academic Press.

Primljeno: 20.05.2017.

Odobreno: 25.06.2017.

Korespodencija:

Stojanović Darko, student doktorskih studija

Fakultet sporta i fizičkog vaspitanja, Univerzitet u Nišu

Niš, Srbija

E-mail: darko87_nish@hotmail.com

Tel: +381666090005 